wad bacilli in milk. The last two weeks he"was in hospital he had no fits, and for a week after returning home he had mone. The intestinal condition was entirely changed under the influence of suitable food, attention to the bowels, and the lactic acid bacilli. But the influence upon the fits was practically nil.

Conolusions. - It will be noticed that the results of these investigations are uniformly negative with one exception. There appears to be a relationship between the fit and a low area-ammonia ratio.

Literature - 1. Herter: Journal of Binlngical Chemistry. January, 1906. 2. Herter and Smith : New York. Medical Journal, August and September, 1892. 3. Laplace : Semaine Médicale. 4. Turner, John
Brit. Med. Jour., March 3rd, 1906.

Liverpool.

\section{Clinical âtes:}

\section{MEDICAL, SURGICAL, OBSTETRICAL, AND THERAPEUTICAL.}

\section{NOTE ON A CASE OF ACUTE ANTRUM OF HIGHMORE WITH EYE COMPLICATIONS.}

BY JoHN R. FOSTER, F.R.C.S. EdiN.,

OPHTHALMTC AND AURAL SURGEON, CAMERON HOSPITAL, WEST HARTLEPOOL。

A WORKMAN was sent to me on June 30th of this year with the following history. Fourteen days prior to his visit to me he had a severe attack of intuenza. On the day following the beginning of this illness he explained to me that he had very acute pain of a neuralgic character, confined to the left side of his face and head. Two days followirg the neuralgia he began to notice that the sight of the left eye was becoming dim, also that his sight was double; this latter feature he especially notice d on descencing the stairs from his room. 1 found his condition as follows:-

The patient was a young man 22 years of age. From the position in which be sat, and the distortion of his face, it was evident that he suffered great pain. His left eye had a marked vertical squint, only the lower half of the cornea being visible. The pupil was dilated and sluggish to strong light, and it was under the circumstances difficult to estimate his vision accurately, but it appeared to be about $6 / 60$. When I palpated between the eyeball and the inferior orbital wall there was a distinct swelling, irregular and firm, only slightly painful on pressure; there was also some oedema of the lower lid, which the patient explained was not so bad as it had been on the previcus day. The fundus of the eye showed the edges of the optic disc blurred and the vessels distended and tortuous; I could not make out any difference in the level of the disc and the surrounding retina. With red and green glasses well-marked diplopia was shown, both horizontal and vertical in character, the vertical being the more marked.

The diagnosis rested, in my opinion, between tumour of the antrum and acute antrum. I punctured the antrum below the inferior turbinate and syringed out some pus with a very offensive smell. It appeared to me that the best thing under the circumstances was to make a good exploratory opening through the canine fossa. I did this and fonnd nothing in the antrum except a small quantity of pus and some polypoidal mucous membrane. A gauze drain was inserted, and in a few days all symptoms disappeared.

West Hartlepool.

\section{RUPTURE OF AN EMPYEMA INTO THE OESOPHAGUS.}

By William A. Bullough, M.Sc., M. B., Ch.B. Vict.

A GIRL, aged 16 months, was admitted to the Royal Albert Edward Infirmary and Dispensary, Wigan, on Feb. 8th, 1911. Her medical attendant had explored the chest and found pus. The child was in an extremely emaciated condition, and cried in a peculiar way that suggested extreme bunger. On exploring the left side of the chest some turbid fluid was withdrawn. A poition of rib was resected, but very little pus was found. The lung was contracted and although a number of adhesions were broken down, did not "come up" well. Next day she continually vomited the milk and other fluids which were got down her throat. At the first dressing it was noted that the discharge resembled curds of milk. Consequently the child was given a little milk to swallow, and thereupon a portion of it came tbrough the wound. The quantity swallowed and the quantity coming through the wound were roughly measured and it was found that about half the milik escaped through the wound. On interrogating the parents it was elicited that the child had been continually vomiting her milk for a week prior to admission. We were of the opinion that it was a case of raptured diverticulum of the osophagus. However, the child died next day and we made a post-mortem examination.

Necrnpsy.- The left lung was contracted and firmly adherent to the posterior pleura. On opening the mediastinum a mass of adhesions was found between the osophagus and the left pleura. An oval-shaped hole was found on the left side of the aesophagns about 3 inches above the diaphragmatic opening. The hole was three quarters of an inch long and a quarter of an inch wide, the long axis being in the axis of the oesophagns. The edges of the hole looked as though it had existed for some little time, being nicely rounded off. No diverticulum was found.

The presumption is that an empyema had burst into the oesophagus, that the pus bad been expectorated by the œsophagus and mouth, and that the child had died from starvation.

I am indebted to Dr. J. Blair for permission to record this case.

Wigan.

\section{Matiral Sorteties.}

\section{ROYAL SOCIETY OF MEDICINE.}

\section{OBSTETRICAL AND GYN ECOLOGICAL SECTION.}

Large Fibro-eystiv Tumour of the Perineum.-Specimens. A mektung of this section was held on Oct. 5 th, Dr. AMAND J. M. RoUTH, the President, being in the chair.

Mr.J. D. MALCoLAI showed specimens and photographs of a remarkable case in which a tumour measuring $37 \frac{1}{2}$ inches in horizontal circumference havg from a woman's buttock to the level of her knees. Her age was 30 ; she had one child, aged 11 years, and six years before admission to the Samaritan Free Hospital she was under the care of an experienced surgeon who found a lax cyst to the left of the vagina and another behind the uterus. It was thought that there was a double vagina, and an incision was made into the lower swelling, but no pus and very little fluid escaped. A year later another surgeon of large experience found three tumours, one in the abdomen, one protruding from the vagina, and one bulging the buttock. After that time the patient did not consult any medical man from July, 1906, until A pril, 1911, when the buttock tumour had attained the enormous dimensions above mentioned. The anus was dragged out of place, and the finger, when inserted into the rectum, did not pass upwards into the body but downwards into the external mass, which had an area of resonance on its upper surface corresponding to the position of the lower bowel. There were also a tumour projecting from the vagina and an ill-defined growth in the abdomen. The removal of the new growths was obviously a very formidable procedure, but as there was no hope of relief except by operation the patient was told that the treatment would be very dangerous, and she still was anxious to have it carried out. There was a tumour in front of the peritoneum below the umbilicus, another behind the uterus, $a$ third $7 \frac{1}{2}$ in. long projecting from the vagina, and the enormous mass of the buttock tumour. These all united in the anterior palt of the pelvis on the left side, and they were removed by combined abdominal and perineal incisions, with the exception of a small part in the pelvis. After much fuid had drained from them the parts removed weighed $39 \frac{1}{2}$ pounds. Three of the tumours were soft very cedematous solids; the large battock growth was partly soft solid and partly cystic. The 